http://dx.doi.org/10.30681/23588403v13i0208

\title{
ASPECTOS HISTÓRICO-SOCIAIS NO CONTO LUÍS SOARES, DE MACHADO DE ASSIS
}

Data de recebimento: $24 / 01 / 2020$

Aceite: $25 / 03 / 2020$

\section{Marieli Paula Folharim THEISEN ${ }^{1}$}

Resumo: Este estudo versa sobre os aspectos histórico-sociais presentes no conto Luís Soares, de Machado de Assis. O trabalho objetiva a investigação de traços de cunho realista no conto, bem como seu contexto histórico, uma vez que apresenta aspectos sociais característicos da sociedade da época. Desse modo, realizou-se uma pesquisa qualitativa. Para a revisão bibliográfica e a sustentação da análise de dados, o referencial teórico foi amparado em obras de Raymundo Faoro (1974), Antonio Candido (2017) e Lourenço Resende da Costa (2014). Ao desenvolver a análise, constatou-se que o conto Luís Soares apresenta características do realismo machadiano, além de ilustrar o comportamento da elite do século XIX.

Palavras-chave: Machado de Assis; Luís Soares; História; Sociedade, Século XIX.

Abstract: This study verse on the historical-social aspects presente in the tale Luís Soares, by Machado de Assis. The work aims to investigate realistic traits in the tale, as well as its historical context, since it presentes social aspects charateristic of the society of the time. Thus, a qualitative research was carried out. For the bibliographic review and support of the data analysis, the theoretical framework was supported by works by Raymundo Faoro (1974), Antonio Candido (2017) and Lourenço Resende da Costa (2014). In developing the investigation, it can be seen that the tale Luís Soares presents characteristics of Machado's realism, in addition to illustrating the behavior of the nineteenth century elite.

Keywords: Machado de Assis; Luís Soares; History; Society; Nineteenth century.

\section{Introdução}

Considerando as duas fases de Machado de Assis, uma romântica e outra realista (a chamada 'fase madura'), a maioria dos críticos destaca a última como a mais importante e, assim sendo, é a mais estudada. No entanto, alguns trabalhos da fase romântica de Machado, como seus contos, não devem ser deixados de lado, uma vez que já apresentam traços de cunho realista, como Luís Soares.

Nessa perspectiva, este estudo busca analisar o conto Luís Soares de forma a destacar os aspectos realistas presentes no conto, bem como aprofundar o contexto histórico no qual foi

1 - Graduanda em Letras-Língua Portuguesa pela Universidade Regional Integrada do Alto Uruguai e das Missões- campus de Frederico Westphalen. 
escrito. Para tal, os principais autores utilizados foram Raymundo Faoro, Antonio Candido e Lourenço Resende da Costa.

Em seu livro Machado de Assis: a pirâmide e o trapézio (1974), o sociólogo e historiador Raymundo Faoro realiza um estudo sobre a obra de Machado relacionando os textos com a sociedade e as classes do Brasil Império. Dessa forma, seu trabalho é de grande importância para descrever o contexto histórico da narrativa machadiana. Além dele, outro autor importante para este trabalho é Lourenço Resende da Costa, que apresenta maiores noções sobre herança e casamento no conto Luís Soares. Ainda, Antonio Candido em Esquema de Machado de Assis (2017) traz pontos relevantes para alguns "problemas" encontrados na obra de Machado.

Em um primeiro momento, trata-se do estilo machadiano e do contexto histórico no qual foi escrito o conto. Após, versa-se sobre o conto analisado, ressaltando seus aspectos histórico-sociais.

\section{Estilo Machadiano}

Antes de qualquer coisa, é preciso considerar o estilo machadiano presente no conto Luís Soares, publicado no livro Contos Fluminenses, lançado em 1870. Nessa época, Machado de Assis ainda estava em sua primeira fase, considerada romântica. Contos Fluminenses foi a sua primeira coletânea de contos dentre a qual os mais conhecidos são Miss Dollar e Luís Soares.

Apesar de essa coletânea fazer parte de sua primeira fase, Machado de Assis já apresentava alguns traços de sua fase realista - iniciada em 1881 com a publicação de Memórias Póstumas de Brás Cubas - como indica Alfredo Bosi: “[...] À primeira leitura, ou há evidências de máfé, ou evidência de lisura. Nem por isso alguns dos Contos Fluminenses deixam de ser histórias de suspeita e engano". (BOSI, Alfredo, 2003, p.77)

De certa forma, as histórias apresentadas em Contos Fluminenses possuem dado cunho moral: em Luís Soares, a personagem principal é castigada por fingir amar sua prima em razão de uma herança, por exemplo. No entanto, Machado não demonstra assim ser um romântico moralista porque, segundo Bosi (2003, p.79): "Machado de Assis nunca foi, a rigor, um romântico (o Romantismo está às suas costas); mas sim pelo gosto sapiencial da fábula que traz, na coda ou nas entrelinhas, uma lição a tirar.” O que Machado objetivava não era simplesmente dar uma lição de moral aos seus leitores, mas sim escrever algo que os fizesse refletir. 
Nesse sentido, Machado não chocava a família tradicional da época, porque, por mais que não fosse um romântico, também deixava sua "ironia fina" nas entrelinhas, como afirma o crítico Antonio Candido:

Num momento em que os naturalistas atiravam ao público assustado a descrição minuciosa da vida fisiológica, ele timbrava nos subentendidos, nas alusões, nos eufemismos, escrevendo contos e romances que não chocavam as exigências da moral familiar. (CANDIDO, 2017, p. 18-19)

O autor também sustenta que o gosto de Machado pelas sentenças morais dava um tom de sabedoria ao texto, gosto esse que herdou das leituras de literatura francesa clássica e da Bíblia.

Em seu Esquema de Machado de Assis (2017), Candido não menciona os primeiros contos de Machado, apenas focando nos contos da sua fase realista, como aponta França (2008). No entanto, o crítico esquematiza seis casos (problemas) que ele observou na obra de Machado, que merecem destaque, apesar de o texto ignorar os primeiros escritos do autor:

1. Construção da identidade. Candido toma como exemplo o conto $O$ espelho para elucidar a personalidade formada pelo próprio indivíduo e a formada pelo que os outros veem dele.

2. Relação entre o fato real e o fato imaginado. Para exemplificar esse problema o autor usa o romance Dom Casmurro, uma vez que não há delimitações entre o que aconteceu e o que Bento Santiago acha que aconteceu, a mesma linha tênue entre razão e loucura.

3. Sentido do ato. Para esse problema, Candido utiliza o romance Esaú e Jacó e demonstra que a rivalidade entre os dois irmãos, Pedro e Paulo, faz com que estes ajam de formas opostas, mas mesmo assim amam uma só mulher: Flora. Esta não consegue escolher apenas um deles porque se sente completa com ambos e, uma vez que o ato é a opção, ela morre sem escolher.

4. A procura pela perfeição. Nesse caso, Candido destaca o conto Um homem célebre, que trata de um compositor de polcas que não gosta de suas composições, já que preferia compor uma peça erudita. No entanto, ele não consegue compor nada como Beethoven ou Mozart, mas sim mais polcas, fazendo o que lhe é possível, não o que lhe agradaria.

5. A relatividade dos atos. Candido usa como exemplo Memórias Póstuma de Brás Cubas para demonstrar que até mesmo a morte é conceituada de forma relativa. Além 
desse exemplo, também toma o conto Singular ocorrência, que mostra as contradições na alma.

6. A transformação do homem em objeto do homem. Para esse caso, o autor aponta Quincas Borba e Memórias Póstumas de Brás Cubas, nos quais o filósofo Joaquim Borba dos Santos (Quincas Borba) cria a teoria do Humanitismo e acaba ficando louco. Outro exemplo é o conto A causa secreta, que ilustra a transformação do homem em um instrumento de outro homem, assim como um animal violentado.

Dentre os problemas citados por Candido, o que aparece no conto Luís Soares é apenas o último: a tomada do homem como objeto do próprio homem, uma vez que Soares toma sua prima Adelaide como um objeto para ascender.

Além desses traços presentes na obra de Machado, o crítico Alfredo Bosi também ressalta a condição das suas primeiras personagens, que necessitavam adquirir um status alto na sociedade:

Nos Contos fluminenses e nas Histórias da meia-noite a maior angústia, oculta ou patente, de certas personagens é determinada pelo horizonte de status; horizonte que ora se aproxima, ora se furta à mira do sujeito que vive uma condição fundamental de carência. É preciso, é imperioso supri-la, quer pela obtenção de um patrimônio, fonte por excelência dos bens materiais, quer pela consecução de um matrimônio com um parceiro mais abonado. (BOSI, 2003, p. 75-76)

No caso de Luís Soares, o protagonista toma como primeira opção voltar a falar com o tio, para que este lhe deixasse a herança quando morresse. No entanto, após ver que o êxito nessa ideia poderia demorar, cogita casar com a prima Adelaide, a conselho de seu amigo Pires.

Após essas considerações a respeito do estilo machadiano, é relevante destacar também o contexto histórico no qual foi escrito o conto Luís Soares, levando em consideração a sociedade da época e seus costumes.

\section{CONTEXTO HISTÓRICO}

O conto Luís Soares é de 1869 e faz parte da coletânea Contos Fluminenses, publicada em 1870. Nessa época o Brasil ainda era um Império e baseava-se em uma economia colonial, que, segundo Schwarz: "produziu, com base no monopólio da terra, três classes de população: o latifundiário, o escravo e o 'homem livre', na verdade dependente." (SCHWARZ, 2000, p.15). Nesse sentido, é importante evidenciar os papéis que exerciam as personagens principais do conto: Luís Soares, um jovem boêmio que gasta a herança deixada pelo pai; Adelaide, uma moça com poucos contos de réis como dote, que vive com seu tio; o tio de 
Luís e de Adelaide, o Major Vilela, homem autoritário que possui um posto importante destinado aos que mantinham a ordem.

Luís Soares é um mancebo herdeiro de pai rico, que, por viver esbanjando dinheiro, sem se importar em trabalhar, acaba perdendo toda a sua fortuna. Para ele, a pobreza é o fim de sua vida: prefere morrer a ser pobre. Além disso, tinha a fama de gastador e rico, fama esta que o fez conhecido na sociedade e, agora, a pobreza daria o que falar, como sustenta Faoro (1974):

Os valores têm três escalas: Luís Soares, estroina, dissipador, boêmio, recebe um dia
uma notícia trágica: o banco lhe comunica estar seu saldo reduzido a seis contos.
Seis contos seriam alguma coisa, com uma renda de trezentos e sessenta mil réis por
ano, trinta mil réis por mês, o miserável salário de um trabalhador rural. Para Luís
Soares, esquivo ao trabalho, gastador sem cálculo de futuro, seria a vergonha.
(FAORO, 1974, p. 213)

Adelaide é uma moça de vinte e quatro anos e vive com seu tio e com uma parenta, Sra Antônia de Moura Vilela. Apesar de muito bonita, a moça possui apenas trinta contos de réis como dote, quantia que, para alguns como Soares, não era muito significativa. Adelaide é uma típica moça do século XIX e, assim como as outras, não possui a liberdade dada a Soares, por exemplo, como salienta Costa: “A licenciosidade das personagens masculinas na literatura machadiana é conhecida. [...] Podemos perceber que nenhuma dessas personagens tem sua posição ou reconhecimento social ameaçada ou desprestigiada, pois trata-se de homens." (COSTA, 2014, p.106).

Já o Major Luís da Cunha Vilela é um senhor com cerca de sessenta anos, alegre e severo ao mesmo tempo, que prega o tradicionalismo. O posto de major era um traço da autoridade utilizada para manter a ordem e assegurar as instituições: “Autoridade primária, mais mando do que autoridade. Mesmo os elementos urbanos dessa organização, criada em 1831 em substituição às milícias coloniais, mostram o traço autoritário da sua ambientação rural." (FAORO, 1974, p. 37) De acordo com Raymundo Faoro (1974), passa-se uma ideia de que a autoridade exalta as pessoas, autoridade rural que está próxima da violência e, portanto, obter o posto de major era, além de uma grande honraria, uma forma de poder.

Não era apenas a personagem Luís Soares quem vivia de forma ociosa: no século XIX, as famílias abastadas viviam sem trabalhar e, se trabalhavam, eram em cargos 'superiores', como o próprio major Vilela. Outro cargo presente no conto, almejado pelo major para o sobrinho, era a política, já que elevava ainda mais o nome da família, consoante Costa (2014):

Numa sociedade que demonstra pouco apego à ética do trabalho, a vida parlamentar era o caminho natural para fugir da obscuridade e ilustrar ainda mais o nome da família. A Política era a ambição de parte das elites brasileiras e exercia uma fascinação sobre os homens dessas elites; homens que execravam o trabalho viam na 
vida pública um dos poucos meios de atuação digna de suas estirpes. (COSTA, 2014, p. 106)

Um aspecto que também ilustra a sociedade da época presente no conto é o casamento, uma vez que era apresentado como uma forma de unir pessoas com o mesmo poder aquisitivo, a fim de multiplicar esse poder e ser ainda mais influente. Como bem aponta Foro (1974), não há disfarces nem sentimentos, apenas a busca pelo patrimônio, pelos bens e pelo dinheiro: “O casamento é um negócio, como um negócio é a herança, mas negócios que tocam em coisas sagradas, o amor e a morte.” (p. 224).

Além desse traço, percebe-se que a herança é outro modo de permanecer em uma vida luxuosa sem esforço algum. No conto Luís Soares, esse traço é visto de duas formas: com Soares, que dissipou sua herança gastando sem medida e com Adelaide, que recebeu uma herança muito maior do que imaginava, dando-lhe a possibilidade de viver sua vida sem depender de um casamento com alguém mais afortunado. A questão da herança é comum na obra de Machado, estando presente também nos romances Quincas Borba e Helena, por exemplo, demonstrando que Machado de Assis já observava os aspectos sociais que o cercavam antes de sua fase madura.

Assim, vê-se que Machado de Assis ilustra as relações, os interesses e os meios de vida da elite do século XIX. Ademais, também elucida as extravagâncias e as orgias que a alta sociedade realizava, assim como Soares: almoços, teatro, festas e ópera, todos os luxos de alguém que não precisava se preocupar com dinheiro. A única preocupação da aristocracia era perpetuar seu status na sociedade por meio do casamento bem arranjado e fazer investimentos.

Em suma, Machado, mesmo não estando em sua fase madura, apresenta ao leitor, nas entrelinhas, uma sociedade com todos os seus vícios e, portanto, seu trabalho em Luís Soares não deve ser deixado de lado por fazer parte da fase romântica do autor, sendo um texto que já possui traços do realismo machadiano.

\section{LUÍS SOARES}

O conto, como o próprio nome já diz, trata de Luís Soares, um mancebo de trinta anos que vive conforme seus instintos: troca o dia pela noite, não possui emprego e esbanja dinheiro com festas, teatros e ceatas. Após um considerável tempo de dissipação, Soares recebe uma carta do banqueiro dizendo que ele possui apenas seis contos de réis, quantia que, para o moço, é o mesmo que possuir seis vinténs. 
Achando-se perdido, Soares pede um conselho ao seu amigo de orgias, José Pires, que apresenta ao rapaz três opções: ir para Nova Iorque arranjar uma fortuna; casar com uma prima rica; pedir perdão ao tio e tornar-se seu herdeiro universal. De todos os meios, Soares gosta mais do último. Ele vai até a casa do tio e prostra-se diante dele. O tio considera sincero o seu arrependimento e lhe arranja um emprego em uma repartição.

O seu tio, Major Vilela, vivia com a sobrinha Adelaide e uma velha parenta. Adelaide amara o primo Soares há algum tempo, ao passo que ele trata o casamento com ela como um mau negócio, considerando o dote de trinta contos de réis.

Após observar Soares e Adelaide, o major Vilela percebe o amor da moça pelo rapaz e propõe o casamento. $\mathrm{O}$ moço tenta se esquivar, mas acaba tendo que aceitar a proposta se espera parte da herança. No entanto, um antigo amigo do pai de Adelaide aparece com uma carta, dizendo que a moça ganharia trezentos contos de réis de herança caso cumprisse com a vontade de seu falecido pai: casar-se com Soares. Logo após descobrir tal empresa, Soares toma como resolução casar-se com ela mediante os trezentos contos e começa a sondar a moça.

Adelaide percebe as intenções de Soares e conta tudo ao tio que, por sua vez, relata a Anselmo, o amigo do pai de Adelaide. Este decide dar a Adelaide a herança mesmo não havendo casamento e propõe que o major e a família viagem à Europa. Soares não é convidado para a viagem e, vendo-se só e pobre, comete suicídio.

Em síntese, o texto apresenta um rapaz que acaba com a sua fortuna e busca outros meios para voltar a ser rico. Contudo, por pensar apenas em dinheiro, perde também as suas chances de enriquecer novamente, preferindo o suicídio a uma vida de trabalho.

Por mais que a história passe uma lição de moral, também ilustra certos aspectos da sociedade da época, como a herança e o casamento, citados anteriormente. Além deles, as relações também são tomadas como um ponto chave na narrativa: ao final, Pires descobre o suicídio do amigo e conta à Vitória:

- Sabes de uma cousa? perguntou ele.

- Não. Que é?

- O Soares matou-se.

- Quando?

- Neste momento.

- Coitado! É sério?

- É sério. Vais sair?

- Vou ao Alcazar.

- Canta-se hoje Barbe-Bleue, não é?

- É.

- Pois eu também vou.

E entrou a cantarolar a canção de Barbe-Bleue. 
Luís Soares não teve outra oração fúnebre dos seus amigos mais íntimos. (ASSIS, 1994, p.37-38)

Nenhuma expressão de tristeza ou consternação: a amizade de Soares e Pires só existia quando estavam juntos nas festas e nos teatros. Machado de Assis representou com sarcasmo a indiferença de Pires em relação à morte de Soares, demonstrando um aspecto realista no conto, já que esse estilo sarcástico aparecerá muito nos seus romances da fase madura.

O que Machado também relata é a dualidade do protagonista quando este tenta conseguir a estima do tio e aceita um emprego:

Havia já cinco meses que o sobrinho do Major Vilela se achava empregado, e ainda
os chefes da repartição não tinham tido um só motivo de queixa contra ele. A
dedicação era digna de melhor causa. Exteriormente via-se em Luís Soares um
monge; raspando-se um pouco achava-se o diabo. (ASSIS, 1994, p. 27)

Para os outros, Soares parecia uma nova pessoa que, arrependida da vida que levara, buscava uma nova, quando, na verdade, ele almejava a herança do tio que, mais cedo ou mais tarde, morreria. É a dualidade do ser: o exterior e o interior, o que os outros veem e o que realmente é.

Soares tomou como resolução casar-se com a prima a fim de obter os trezentos contos deixados pelo pai da moça e, se antes ele se esquivava, agora a sondava com grande interesse: “"Trezentos contos, pensava o rapaz, é quanto basta para eu ser mais do que fui. O que não hão de dizer os outros!' Antevendo uma felicidade que era certa para ele, Soares começou o assédio da praça, aliás praça rendida" (ASSIS, 1994, p. 34). O que o rapaz não esperava era a indiferença da moça que, percebendo suas intenções, optou por não realizar o casamento.

Enfim, Soares não consegue o consórcio e acaba pobre, sem esperanças de mudar a sua situação. A busca pelo poder e pelo dinheiro termina com o suicídio, já que a pobreza não é uma opção para Soares, que faz parte de uma elite que tem aversão pelo trabalho.

\section{CONSIDERAÇÕES FINAIS}

Diante do exposto, após todas as observações a respeito de certos aspectos do conto, pôdese observar que Machado representou a sociedade do século XIX em Luís Soares, demonstrando todos os vícios da elite da época e suas formas de permanecer no poder. Além disso, evidenciou as relações e como tudo girava em torno do dinheiro, tratando, de forma sarcástica, a notícia da morte de Soares dada aos seus amigos.

Constatou-se, principalmente, que, mesmo fazendo parte da fase romântica de Machado de Assis, o conto Luís Soares apresenta muitos traços de cunho realista, que já manifestavam 
sementes do realismo machadiano de 1880. Assim, não é apenas um conto romântico moralista, mas sim um texto que reflete o momento em que foi escrito, fazendo uso da verossimilhança para representar a realidade nas entrelinhas.

\section{Referências}

ASSIS, Joaquim Maria Machado de. Obra completa. Rio de Janeiro: Nova Aguilar, 1994. 2 v. Disponível em: <machado.mec.gov.br>. Acesso em: 20 jan. 2020.

BOSI, Alfredo. O enigma do olhar. São Paulo: Editora Ática, 2003.

CANDIDO, Antonio. Esquema de Machado de Assis. In: Vários Escritos. Rio de Janeiro: Ouro sobre Azul, 2017.

COSTA, Lourenço Resende da. Casamento, herança e negócios no conto Luís Soares, de Machado de Assis. Todas As Musas, v. 2, n. 5, p.101-111, jan-jun 2014. Semestral. Disponível em: <https://www.todasasmusas.com.br/10Lourenco_Resende.pdf>. Acesso em: 16 jan. 2020.

FAORO, Raymundo. Machado de Assis: a pirâmide e o trapézio. São Paulo: Companhia Editorial Paulista, $1974 . \quad$ Disponível em: <https://bdor.sibi.ufrj.br/bitstream/doc/403/1/356\%20PDF\%20-\%20OCR\%20-\%20RED.pdf> Acesso em: 12 jan 2020.

MELO FRANÇA, Eduardo; ANCO, Marcio Tenório Vieira. Ruptura ou amadurecimento? Uma análise dos primeiros contos de Machado de Assis. 2008. Dissertação (Mestrado). Programa de Pós-Graduação em Letras, Universidade Federal de Pernambuco, Recife, 2008. Disponível em: 〈https://repositorio.ufpe.br/bitstream/123456789/7455/1/arquivo3549_1.pdf> Acesso em: 09 jan 2020.

SCHWARZ, Roberto. Ao vencedor as batatas: forma literária e processo social nos inícios do romance brasileiro. $5^{\text {a }}$ ed. São Paulo: Duas Cidades, 2000. 